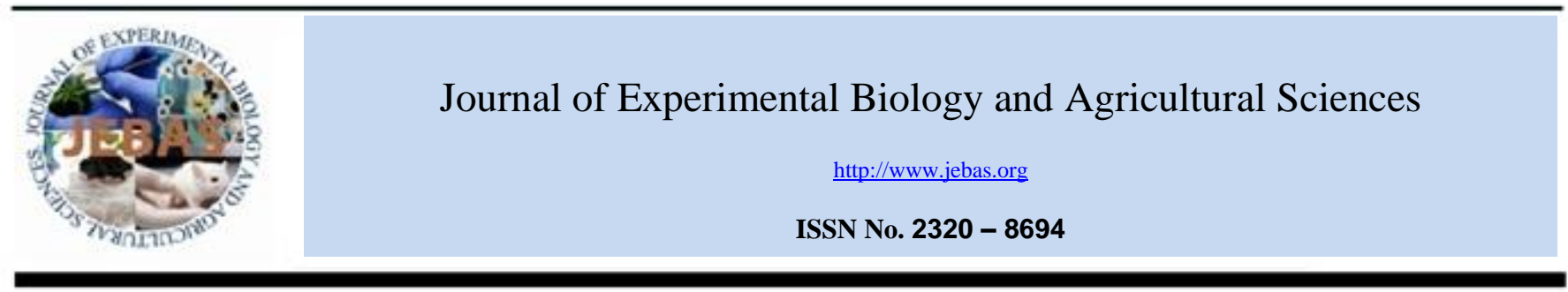

\title{
EFFECT OF Citrus reticulata BLANCO LEAF EXTRACT ON SEED GERMINATION AND INITIAL SEEDLING GROWTH PARAMETERS OF FIVE HOME GARDEN FOOD CROPS
}

\author{
Sahoo U K ${ }^{*}, 1$, Jeeceelee $\mathrm{L}^{1}$, Lallinrawna $\mathrm{S}^{2}$ and Muthukumaran R B ${ }^{2}$ \\ ${ }^{1}$ Department of Forestry, Mizoram University, Aizawl, Mizoram - 796 004, India \\ ${ }^{2}$ Department of Chemistry, Mizoram University, Aizawl-796004, India \\ Received - September 11, 2015; Revision - October 16, 2015; Accepted - December 06, 2015 \\ Available Online - December 15, 2015
}

DOI: http://dx.doi.org/10.18006/2015.3(6).517.528

KEYWORDS
Citrus reticulata Blanco
Leaf extract
Germination
Root length
Shoot length

\begin{abstract}
Effect of various concentrations of Citrus reticulata Blanco leaf extract was studied on seed germination and seedling growth of five common home garden food crops viz. Capsicum annum L. (Chilli), Glycine max (L.) Merr. (Soybean), Zea mays L. (Maize), Oryza sativa L. (Rice), and Abelmoschus esculentus (L.) Moench (Lady's finger) in laboratory using Petri dishes with sterilized absorbent cotton. The experiment was conducted under natural light dark cycle with three replicates. The seeds were regularly irrigated with the $C$. reticulata extracts. Results of the study revealed that the aqueous leaf extract of $C$. reticulata have significant effect on seed germination and plant growth. The highest inhibitory effect (55\%) of leaf extract was reported on seed germination of chilli at $80 \%$ extract concentration and the lowest $(3.33 \%)$ in maize at absolute concentration. The highest inhibitory effect $(65.26 \%)$ on shoot elongation was recorded in the maize at $80 \%$ extract concentration while at this concentration, maximum inhibition $(58.52 \%)$ on root elongation was registered in soybean. Under pot culture, shoot length in paddy and dry matter accumulation in chilli were inhibited at all concentration. In general higher concentrations had stronger inhibitory effects while in some cases the lower concentration had stimulatory effects. The study also revealed that the inhibitory effect was much pronounced in shoot and root lengths as compared with the germination of the receptor crops. The studies provide the evidence of $C$. reticulata having allelopathic potential which reduces the germination as well suppresses the growth and development of the test crops.
\end{abstract}

* Corresponding author

E-mail: uksahoo_2003@rediffmail.com (Sahoo U K)

Peer review under responsibility of Journal of Experimental Biology and Agricultural Sciences.

Production and Hosting by Horizon Publisher (http://publisher.jebas.org/index.html).

All rights reserved.
All the article published by Journal of Experimental Biology and Agricultural Sciences is licensed under a Creative Commons Attribution-NonCommercial 4.0 International License Based on a work at www.jebas.org.

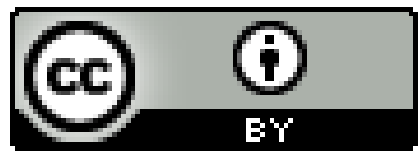




\section{Introduction}

Citrus reticulata Blanco (Mandarin orange) is one of the most widely grown fruit crops in most of the agroforestry systems practiced in Mizoram, India. These plants are large evergreen shrubs or small trees, with spiny shoots, reaching 5-15 $\mathrm{m}$ tall. Incorporation of these woody perennials in agroforestry system increases overall production; however they may impose some adverse impact on the understorey crops through allelopathic interaction (Gill, 1992; Mughal, 2000). This adverse effect is resulted of release of secondary metabolites referred to allelochemicals involving in interspecific chemical interactions (allelopathy) affecting the growth and development of component plants (Bhatt \& Todaria, 1990; Rafiqul Hoque et al., 2003; Sahoo et al., 2007; Sahoo et al., 2010). Allelopathic properties of various trees species such as Magnifera indica, Areca catechu, Eucalyptus spp and Acacia spp have been reported by various researchers (Velu et al., 1996; Sahoo et al., 2010; Sahoo, 2013).

These allelopathic chemicals are distributed in all plant parts (including leaf, flower, bark) at varying concentrations, however leaves are most potent source of these allelochemicals (Rice, 1984; Inderjit, 1996) and have higher inhibitory effects on crops (Seigler, 1996). Plants release many allelopathic compounds to the environment by means of volatilization, leaching from leaves, needles, root and shoot exudation. Allelochemicals are also accumulated in soil by microbial decomposition of plant remains, especially by degradation of lignin. These chemicals are known to affect seed germination, growth, development, distribution and reproduction of many plant species (Inderjit \& Malik, 2002). Phenolics, terpenoids and alkaloids chemicals released from these plants have inhibitory effect on the germination and seedling growth (Narwal, 1994; Hättenschwiler \& Vitousek, 2000). Laboratory bioassays and pot culture are significant part of allelopathic research which assess either inhibitory or stimulatory effect of plant extracts and the effects are generally concentration dependent (Daniel, 1999). Besides seedling mortality, the reduced seedling vigour of many recipient plants is attributed to the accumulation of toxic or poisonous chemicals of the donor in the soil (Chou, 1992; Assaeed \& Al-Doss, 1997; Rafiqul Hoque et al., 2003). Increased accumulation of allelochemicals in soil nevertheless depends on their rate of production in plants, leaching amount and their combination time (May \& Ash, 1990; Narwal, 1994).

It is also reported that Citrus family contains a variety of phytochemical compounds of both volatile and non-volatile in different parts like leaves, fruits, fruit peel, bark, etc. These phytochemicals have different properties like antifungal, antibacterial, anticancerous, antitumorogenic, antimicrobial, antimitotic, allelopathic (Cvetnic \& Vladimir-Knezević, 2004; Wungsintaweekul et al., 2010). Most commonly reported compound in Rutaceae family is limonoids which belongs to terpenoids chemical family. Jayaprakash et al. (1997) reported 38 limonoids from the Citrus family and its hybrids. Darjazi (2013) identified 47 volatile components, 24 oxygenated terpenes and 23 non-oxygenated terpenes from the sweet orange leaves using water distillation through GC-MS analysis. In many Citrus plants limonin and nomilin limonoids are reported at very high concentrations (Sawbe et al., 1999). It was reported that $C$. hystrix peel and leaf showed the presence of citronellal (about 23\%) as major constituent (Wungsintawwkul et al., 2010) and the trace components found in the oil of $C$. hystrix peel were L-linalool (4.22\%), pinene $(1.82 \%)$ and limonene $(1.13 \%)$. Citrus spp are also reported to induce some inhibitory effect on some plants which can be accounted to the presence of different phytochemicals. For example, peel extracts from Citrus junos has shown growth inhibitory effect on tested 38 crop species (Fujihara \& Shimizu, 2003) and another Citrus fruit peel has inhibited the growth of the roots of lettuce seedlings (Kato-Noguchi \& Tanaka, 2003).

Although, many researches have been done on microbial activities and anti-cancerous aspects of Citrus reticulata but very less attention is given on the allelopathic aspect of this species. C. reticulata is a major component fruit crop in traditional agroforestry systems in Mizoram and also serve as cash generation source. The objective of the present study was to elucidate the allelopathic potential of different concentration of $C$. reticulata leaf extracts on five common agricultural crops and to develop efficient tree- crop management in agroforestry system of Mizoram.

\section{Materials and Methods}

\subsection{Plant Extracts}

Leaves of mature $C$. reticulata Blanco tree (approx. 10 years old) were collected from the home gardens of Aizawl District $\left(92^{0} 38^{\prime}\right.$ to $92^{\circ} 42^{\prime} \mathrm{E}$ longitude and $23^{\circ} 42^{\prime}$ to $23^{\circ} 46^{\prime} \mathrm{N}$ latitude $950 \mathrm{~m}$ above sea level). The leaves from the top, middle and bottom of the selected tree canopy were plucked, mixed in equal proportions and air dried for seven days. C. reticulata was used as donor plant and the receptor agricultural crops used for the experiments were local variety of chilli (Capsicum annum L.), soybean (Glycine max (L.) Merr.), maize (Zea mays L.), paddy (Oryza sativa L.) and lady's finger (Abelmoschus esculentus (L.) Moench). The aqueous extracts were prepared by adding $100 \mathrm{~g}$ crushed dried mature leaves powder in $500 \mathrm{ml}$ of distilled water $(1: 5 \mathrm{w} / \mathrm{v})$, soaked for $24 \mathrm{~h}$ at room temperature, subsequently, filtered using ordinary filter paper. Further, the filtrate was diluted by adding distilled water to make three more concentrations viz. 20, 40, and $80 \%$ and these were stored in dark conical flasks to irrigate the seeds. The experiment included five treatments viz Control (distilled water), 20, 40, 80 and 100\% extract solution used in triplicate. 
2.2 Bioassays

Ten seeds of each food crops were placed in sterilized Petriplates $(90 \mathrm{~mm} \times 15 \mathrm{~mm}$ ) containing absorbent cotton which was spread evenly on the surface and saturated with the respective concentration of $C$. reticulata extracts. The experiment involved three replications for each leaf extract concentration and control (distilled water) and kept under natural light/dark cycle with temperature ranging from 25$30^{\circ} \mathrm{C}$. Observation was made every day and the germinated seeds were counted daily and recorded till $5^{\text {th }}$ day. The emergence of radicle from the seed was considered as seeds germinated. Leaf extract/distilled water was added just to moisten the seeds when required. The measurement of root and shoot length was done on the $10^{\text {th }}$ day. The magnitude of inhibition versus stimulation was compared by Response Index (Sahoo et al., 2007) and the Relative Elongation Ratio of shoots and roots of crops was calculated using standard formula given by Sahoo et al. (2010).

\subsection{Pot culture}

The collected leaf samples were air-dried, grinded and the extracts were prepared as per laboratory bioassays from which different concentration were made by further dilution. Poly pots were prepared using $5 \mathrm{~kg}$ mixture of garden soil, FYM and sand in 3:1:1 ratio in which 3 seeds of each food crop was sown, irrigated with $300 \mathrm{ml}$ of water. Each treatment was replicated 10 times. The poly pots were placed in green house and irrigated twice per week with $100 \mathrm{ml}$ of the extracts and monitored for a period of 30 days. Separate control set of experiment was also performed. Shoot and root lengths of the seedlings were recorded on the $30^{\text {th }}$ day and the dry matter was estimated after carefully cleaning the excavated ten seedlings of each test crop.

2.4 Isolation and purification of allelochemicals
All solvents used in the present study were of analytical grade and were purchased from Merck Specialities Pvt. Ltd., Mumbai. Silica gel mesh 60-120 (for Column Chromatography) was purchased from SD fine Chemicals Ltd., Mumbai and mesh size 100-200 from Himedia Laboratories Pvt. Ltd., Mumbai. Aluminium backed pre coated silica gel 60 $\mathrm{F}_{254}$ plates were purchased from Merck Specialities Pvt. Ltd., Mumbai. Sephadex LH-20 was procured from Sigma Aldrich, Bangalore. Water was purified by a Milli-Q system from Millipore (Bangalore).

The collected leaves of $C$. reticulata were cleaned, washed with water and dried under shaded conditions with occasional shifting and then powdered with a mechanical grinder. The pulverized material was passed through sieve number 40 and stored in airtight container. The dry powdered material of $C$. reticulata leaves were extracted successively with methanol by maceration followed by extraction with an aqueous solvent mixture of methanol and water (50:50) for $24 \mathrm{~h}$ at room temperature. The extraction was carried out exhaustively and the solvents were recovered by distillation under reduced pressure using a rotary evaporator. The concentrated foliar extracts were kept in refrigerator at $4{ }^{\circ} \mathrm{C}$ for further use.

The foliar extract was sequentially partitioned between water and chloroform as well as using water and ethyl acetate to remove chlorophylls, less polar flavonoids and other non-polar compounds from the mixture. Briefly, the dried and powdered methanolic and 50\% methanolic plant foliar extracts were dissolved in $500 \mathrm{ml}$ water and heated in water bath for $30 \mathrm{~min}$ at $50{ }^{\circ} \mathrm{C}$. The resulting clear solution was partitioned thrice with chloroform for the removal of chlorophyll. The partition was subsequently performed thrice with ethyl acetate. Only Polar fractions, prepared from methanol as well as an aqueous solvent mixture of methanol and water (50:50), were further subjected to chromatographic analysis.

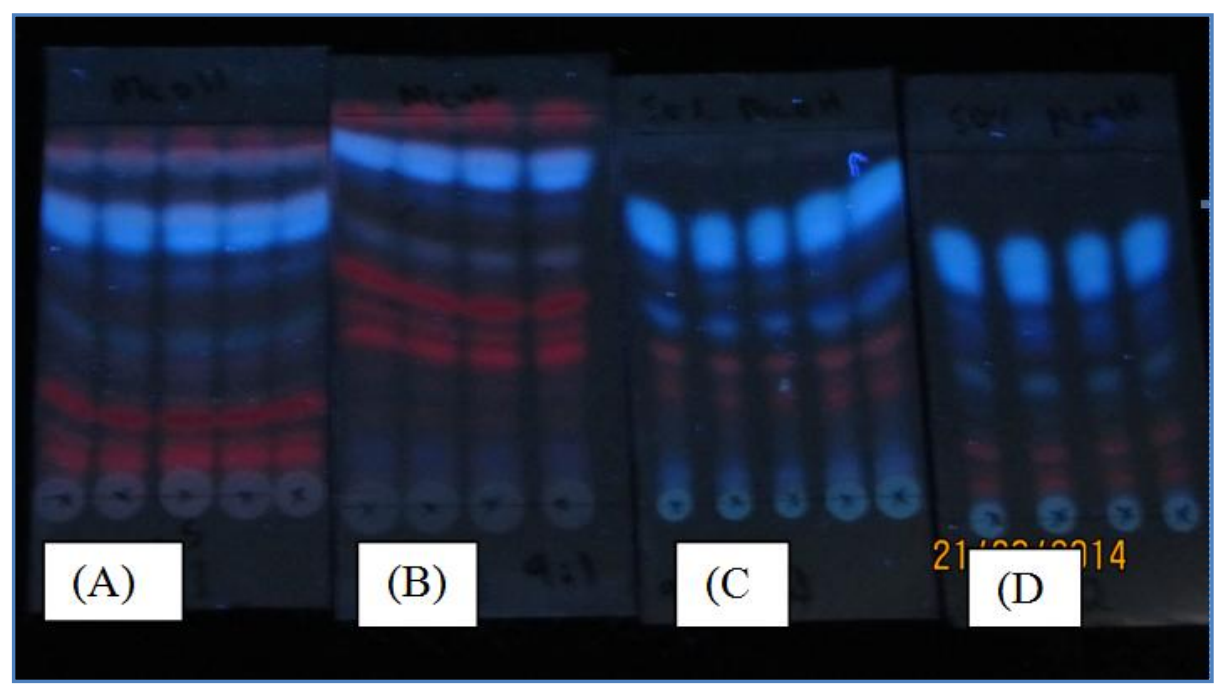

Figure 1 TLC Chromatogram of crude foliar extracts, A \& B Methanol extract, C \& D 50\% methanolic aqueous solution extract. 


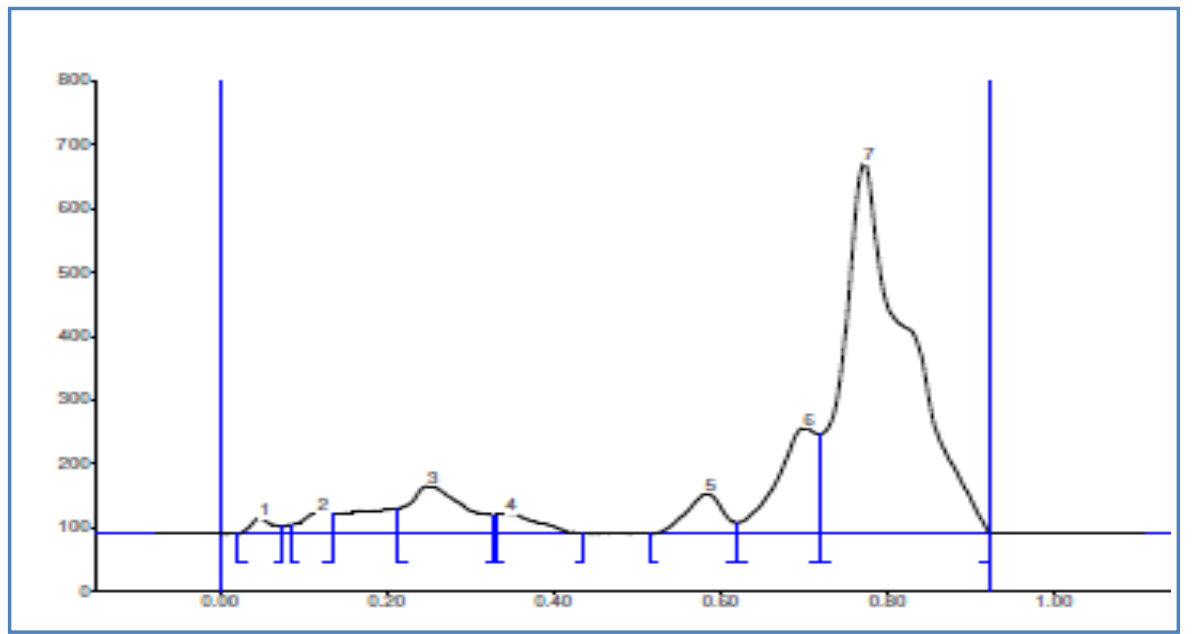

Figure 2 HPTLC profile of 50\% methanolic aqueous solution extract. The numerical represent broad group of chemicals found in the leaf extract of $C$. reticulata.

Normal phase thin layer chromatography (TLC) profiling of the crude foliar extracts were done by spotting the extracts in aluminium precoated TLC silica gel $60 \mathrm{~F}_{254}$ plates activated at $110{ }^{\circ} \mathrm{C}$ for $1 \mathrm{~h}$ (Stahl, 1969) and were eluted with a solvent mixture of chloroform, ethyl acetate and methanol in the ratio of 80:10:10. TLC Chromatograms were developed in chromatographic chambers using selected solvent systems at room temperature and at an angle of $70^{\circ}$. The plates were removed from the chamber after completion of the run and were allowed to dry in air. Well defined spots on TLC plates were detected under illumination at $366 \mathrm{~nm}$ using a JASCO $\mathrm{UV} / \mathrm{V}$ is chamber to observe the presence of different class of compounds in the crude foliar extract.

After the extraction of crude foliar extract, removal of chlorophylls using liquid-liquid extraction methods (vide supra) was done prior to HPTLC analysis. Analytical high performance thin layer chromatography (HPTLC) method was performed with CAMAG TLC Scanner system. TLC plates were developed by employing an eluent mixture of chloroform, ethyl acetate and methanol in the ratio of 80:10:10 as mobile phase, for the chloroform (or ethyl acetate) bleached crude foliar extract. A HPTLC chromatogram consisting of well defined spots was obtained when the chamber was saturated with the eluent mixture for $30 \mathrm{~min}$ at room temperature. The retention factor, $\mathrm{R}_{\mathrm{f}}$ values were calculated by the ratio of the distance traveled by the spot to the distance traveled by the solvent.

The samples were spotted in the form of bands of width $10 \mathrm{~mm}$ with a Camag $100 \mu \mathrm{l}$ syringe on a silica gel- $60 \mathrm{~F}_{254}$ precoated aluminium plate $(10 \mathrm{~cm} \times 10 \mathrm{~cm})$ with $200 \mu \mathrm{m}$ thickness (E. Merck, Germany) using a Camag Linomat V (Switzerland) sample applicator with an injection volume of $10 \mu \mathrm{l}$. The CAMAG TLC scanner was set at $366 \mathrm{~nm}$ at a scanning speed of $20 \mathrm{~mm} / \mathrm{s}$ to acquire the chromatogram. For all experiments, silica gel $60 \mathrm{~F}_{254}$ was used as stationary phase.

\subsection{Statistical analysis}

Results obtained from the experiments were analysed statistically using SPSS 11.1.1 software and were put to variance analysis and least significant difference (LSD) tests to determine any statistical difference existed between the treatments.

3 Results and Discussion

\subsection{Available allelochemicals in leaf extract}

Eight polar fractions were observed under UV illumination, as a result of the fractionation of crude foliar extracts using TLC (Figure 1) and HP-TLC (Figure 2).

Table 1 The Retention factors of various fractions separated from the polar extracts of Citrus reticulata leaves

\begin{tabular}{|cc|}
\hline $\begin{array}{c}\text { Peak/ Major fraction of } \\
\text { chemical groups }\end{array}$ & Retention factor, $\mathbf{R}_{\mathbf{f}}$ \\
\hline $\mathbf{1}$ & 0.05 \\
\hline $\mathbf{2}$ & 0.12 \\
\hline $\mathbf{3}$ & 0.25 \\
\hline $\mathbf{4}$ & 0.34 \\
\hline $\mathbf{5}$ & 0.58 \\
\hline $\mathbf{6}$ & 0.70 \\
\hline $\mathbf{7}$ & 0.77 \\
\hline $\mathbf{8}$ & 0.83 \\
\hline
\end{tabular}

The observation of a range of retention factors (Table 1) is indicative of the presence of a various components. Column chromatography was also employed for the fractionation of polar extracts. 
Table 2 Germination percentages of five home garden crops treated with different concentrations of aqueous leaf extract of $C$. reticulata.

\begin{tabular}{|c|c|c|c|c|c|}
\hline Treatments & Soybean & Maize & Paddy & Chilli & Lady's finger \\
\hline Control & 96.67 & 100.00 & 96.67 & 66.67 & 43.33 \\
\hline 20 Percent & $93.33(-3.45)$ & $100.00(0)$ & $100.0(+3.45)$ & $53.33(-20.0)$ & $46.67(+7.70)$ \\
\hline 40 Percent & $90.00(-6.90)$ & $96.67(-3.33)$ & $96.67(0)$ & $56.67(-15.0)$ & $66.67(+53.85)$ \\
\hline 80 Percent & $90.00(-6.90)$ & $93.33(-6.67)$ & $96.67(0)$ & $30.00(-55.0)$ & $60.00(+38.47)$ \\
\hline 100 Percent & $86.67(-10.34)$ & $96.67(-3.33)$ & $93.33(-3.45)$ & $83.33(+25.00)$ & $56.67(+30.78)$ \\
\hline LSD@5\% & $\mathbf{1 6 . 7 6}$ & $\mathbf{5 . 7 1}$ & $\mathbf{1 1 . 0 6}$ & $\mathbf{1 9 . 6 3}$ & $\mathbf{2 1 . 9 1}$ \\
\hline
\end{tabular}

Table 3 Effects of aqueous leaf extracts on shoot length (in $\mathrm{cm}$ ) of tested crops.

\begin{tabular}{|c|c|c|c|c|c|}
\hline Treatments & Soybean & Maize & Paddy & Chilli & Lady's finger \\
\hline Control & 24.99 & 10.68 & 5.60 & 4.12 & 12.66 \\
\hline 20 Percent & $26.22(+4.92)$ & $10.61(-0.66)$ & $4.77(-14.82)$ & $4.98(+20.87)$ & $12.09(-4.5)$ \\
\hline 40 Percent & $21.06(-11.23)$ & $8.29(-22.38)$ & $4.29(-23.39)$ & $2.79(-32.28)$ & $10.74(-15.17)$ \\
\hline 80 Percent & $17.07(-31.69)$ & $5.35(-49.90)$ & $3.54(-36.79)$ & $1.91(-53.64)$ & $8.69(-31.36)$ \\
\hline 100 Percent & $12.99(-48.02)$ & $3.71(-65.26)$ & $3.24(-42.14)$ & $2.97(-27.91)$ & $6.29(-50.32)$ \\
\hline LSD@ $@$ & $\mathbf{4 . 2 7}$ & $\mathbf{2 . 8 0}$ & $\mathbf{0 . 6 2}$ & $\mathbf{1 . 2 7}$ & $\mathbf{2 . 3 0}$ \\
\hline
\end{tabular}

Values in the parenthesis indicate either inhibitory (-) or stimulatory (+) effects in comparison to control $\left(\mathrm{T}_{0}\right)$ treatment.

The crude extract was applied to the column which was washed with light petroleum ether to remove fats followed by elution with chloroform and methanol (90:10) and methanol for the column adsorbents, silica and Sephadex LH-20, respectively.

When the methanolic extract was applied to silica gel column, there were about 5 components, while using Sephadex LH-20 as an adsorbent, it also showed 4 components. When $50 \%$ methanolic aqueous extract was subjected to fractionation over silica gel 5 components were isolated besides it was separated into 3 components using Sephadex LH-20 gel. The isolation and structural elucidation of these bioactive natural product compounds is important and so further investigation into the purification and identification of these components using preparative column chromatography methods are currently under progress. However, previous research indicated the presence of six aldehyde components (citronellal, decanal, neral, geranial, $\beta$-senesal and $\alpha$-sinensal), thirteen alcohols (linalool, isopulelgol, terpinen-4-ol, $\alpha$-terpineol, myrtenol, (z)piporitol, trans-carveol, ß-citronellol, cis-carveol, nerol, geraniol, linalool, (E)-nerolidal) and five esters (linalyl acetate, terpinyl acetate, citronellyl acetate, neryl acetate, geranyl acetate) from the leaf extract of sweet orange (Darjari, 2013). The concentration of citronellal and geranial was higher in the leaf samples. Among the monoterpene hydrocarbons sabinene was the major component and among sesquiterpene hydrocarbons ( $\mathrm{z}$ )- $\beta$-caryophyllene and ( $\mathrm{z}$ - $-\beta$-farnesene were the major component in the leaf extract of sweet orange. These carbon-based secondary metabolites widespread in plants (Inderjit, 1996) have been described as allelopathic agents affecting the performance of growth, either by inhibiting seed germination, root or shoot elongation (Lodhi, 1978).

\subsection{Bioassay}

\subsubsection{Effects of aqueous leaf extracts on seed germination}

The germination responses to different treatments by the seeds of receptor crops are summarised in Table 2. The study revealed that the different leaf extracts have both stimulatory and inhibitory effect on the crops. Inhibitory effect was observed in all the test crops except in lady's finger which manifested stimulatory response in all treatments, even though the germination percentage was less, significant inhibitory effect was observed in maize and chilli at 80 percent extract concentration. Furthermore, stimulatory effect of extract was observed at lower concentration (20\%) in paddy and lady's finger though not significant. The highest inhibitory effect (55\%) was recorded in chilli at $80 \%$ and the lowest $(3.33 \%)$ in maize at 40 and $100 \%$. Additionally, at $40 \%$ leaf extract, lady's finger recorded maximum seed germination $(53.85 \%)$ when compared to the control. However, no change was observed in maize at $20 \%$ and paddy at $40 \%$ and $80 \%$ (Figure 3).

\subsubsection{Effects of aqueous leaf extracts on shoot elongation}

The shoot lengths of bioassay receptor crop are summarised in Table 3. All the concentration of extract had inhibitory effect on the shoot length $(\mathrm{p}<0.05)$. The highest inhibitory effect was observed at 80 and 100 percent concentration of extract in all the tested crops. Among the tested crops, paddy crop was severely affected by all the concentration of extracts and it inhibited the root elongation significantly. While the extract had stimulatory effect on the chilli and soybean crops at lowest concentration $(20 \%)$ but it is not significantly different from the control. 


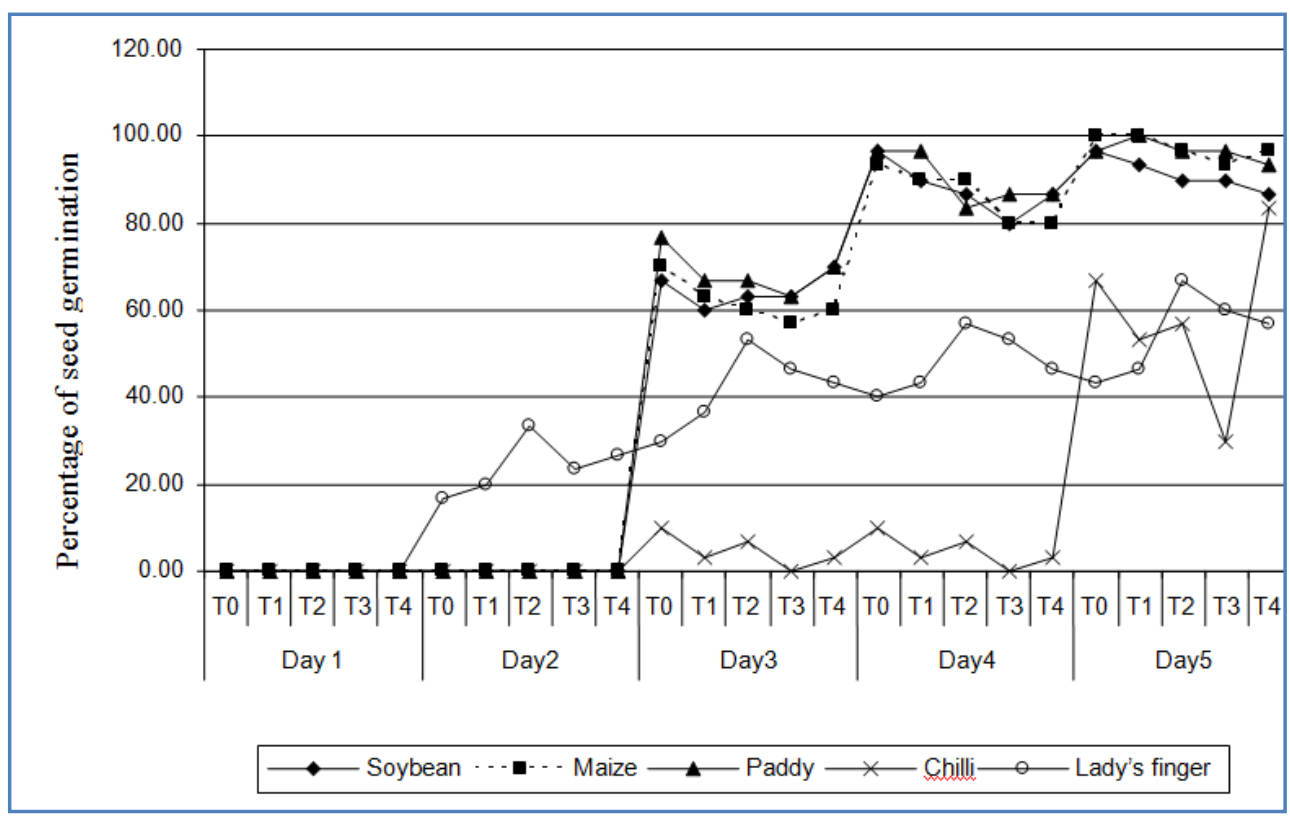

Figure 3 Effects of different concentrations ( $\mathrm{T}_{0}=$ Distilled water, $\left.\mathrm{T}_{1}=20 \%, \mathrm{~T}_{2}=40 \%, \mathrm{~T}_{3}=80 \%, \mathrm{~T}_{4}=100 \%\right)$ of aqueous leaf extract of $C$. reticulata on seed germination of five home garden crops of Mizoram..

Highest $(65.26 \%)$ and lowest $(0.66 \%)$ inhibitory effect of the extract was reported on the maize crop and it was reported at the treatment containing 100 and 20 percent extract respectively. Relative to control, greatest reduction in shoot elongation was observed at higher concentrations. This might be due to reduction in cell division of the tested crops as argued by Gholami et al. (2011) or due to damage of cell membrane by the higher concentration of allelochemicals (Rice, 1984).

The retarded shoot elongation must have been influenced by damage of shoot cells causing interference of nutrient uptake and other growth processes caused by allelochemicals found in the leaf extract of $C$. reticulata. Among the crops, paddy was very sensitive to phytotoxic compounds than other tested crops and thus was severely affected at all leaf extract concentrations.

\subsubsection{Effects of aqueous leaf extracts on root elongation}

Table 4 showed root elongation response to different leaf extract concentration. Root elongation of all the five bioassay species was severely affected in all treatments. The higher concentration caused severe inhibition in root elongation as compared to control. Significant inhibition in all treatments was observed in paddy and lady's finger. However, some stimulatory effect was induced at lower concentration (20\%) in both soybean and chilli even though it did not differ significantly from the control. Statistically, pronounced significant inhibitory effect was found at 40 percent extract and it was followed by 100 and 80 percent treatments. The highest inhibitory effect $(58.52 \%)$ was observed in soybean at treatment containing 100 percent extract while the lowest inhibition $(1.13 \%)$ was found in maize at 20 percent concentration.

Table 4 Effects of aqueous leaf extracts of $C$. reticulata on root length (in $\mathrm{cm}$ ) of tested crops.

\begin{tabular}{|l|c|c|c|c|c|}
\hline Treatments & Soybean & Maize & Paddy & Chilli & Lady's finger \\
\hline Control & 16.13 & 17.74 & 10.11 & 5.09 & 6.85 \\
\hline 20 Percent & $16.66(+3.29)$ & $17.54(-1.13)$ & $7.81(-22.75)$ & $6.15(+20.83)$ & $5.14(-24.96)$ \\
\hline 40 Percent & $14.47(-10.29)$ & $14.05(-20.8)$ & $6.87(-32.05)$ & $3.49(-31.43)$ & $4.26(-37.81)$ \\
\hline 80 Percent & $13.72(-14.94)$ & $13.38(-24.58)$ & $6.35(-37.19)$ & $2.55(-49.90)$ & $3.91(-42.92)$ \\
\hline 100 Percent & $6.69(-58.52)$ & $7.83(-55.86)$ & $4.34(-57.07)$ & $2.54(-50.10)$ & $3.13(-54.31)$ \\
\hline LSD@5\% & $\mathbf{1 . 8 4}$ & $\mathbf{3 . 5 1}$ & $\mathbf{1 . 1 0}$ & $\mathbf{1 . 6 2}$ & $\mathbf{1 . 2 6}$ \\
\hline
\end{tabular}

Values in the parenthesis indicate either inhibitory (-) or stimulatory (+) effects in comparison to control $\left(\mathrm{T}_{0}\right)$ treatment. 


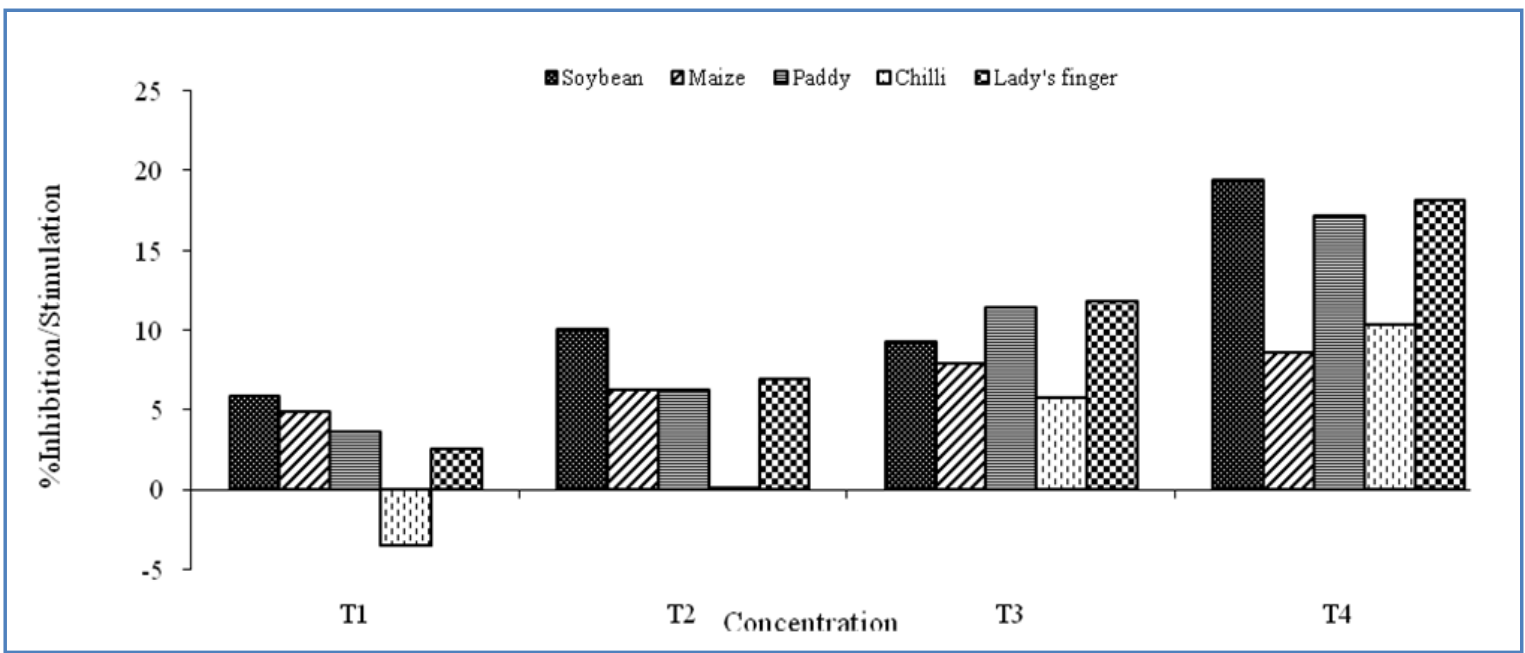

Figure 4 Inhibitory (-) or stimulatory (+) effects on germination percentage of five common homegarden crops treated with different concentrations $\left(\mathrm{T}_{0}=0 \%, \mathrm{~T}_{1}=20 \%, \mathrm{~T}_{2}=40 \%, \mathrm{~T}_{3}=80 \%, \mathrm{~T}_{4}=100 \%\right)$ of aqueous leaf extract of C.reticulata under pot culture.

The study clearly demonstrated the suppressive effect of $C$. reticulata leaf extracts on the germination and seedlings growth (shoot and root elongation) of selected test crops. The results also revealed that the root elongation was inhibited more than the shoot elongation and germination. The greater permeability of allelochemicals to root tissue than shoot tissue (Nishida et al., 2005) caused greater reduction in root length. Root is the first organ to absorb allelochemicals from the extract and this might also explain for a greater effect than the shoot length. All the receptor crops induced significant root and shoot elongation at lower concentrations Various studies on allelopathic effects of $C$. reticulata on fungi suggested a positive correlations between the concentration of Citrus leaf extract and leaf leachate with fungal infection in the soil under the trees (Saeed \& Ramadan, 2006). The populations of
Aspergillus spp. and Penicillium spp. were found increased while the populations of Rhizoctonia solani and Fusarium spp were decreased with the application of leaf extract of C.reticulata. In present study it was reported that extract has suppressive effect and it significantly $(\mathrm{p}<0.05)$ reduced the germination of maize and chilli seeds at 80 percent concentration and overall seedling growth of the receptor plants. Findings of present study were corroborated with the inhibitory effect of leaf extracts of some other plants often grown or cultivated beside crop fields on certain food crops (Rafiqul Hoque et al., 2003). Suppressive effect was increased with an increase of extract concentration indicating that the effect of plant extracts dependent very much on their concentrations. Similar types of observations were reported by various researchers (Chou \& Leu, 1992; Ahmed et al., 2004).

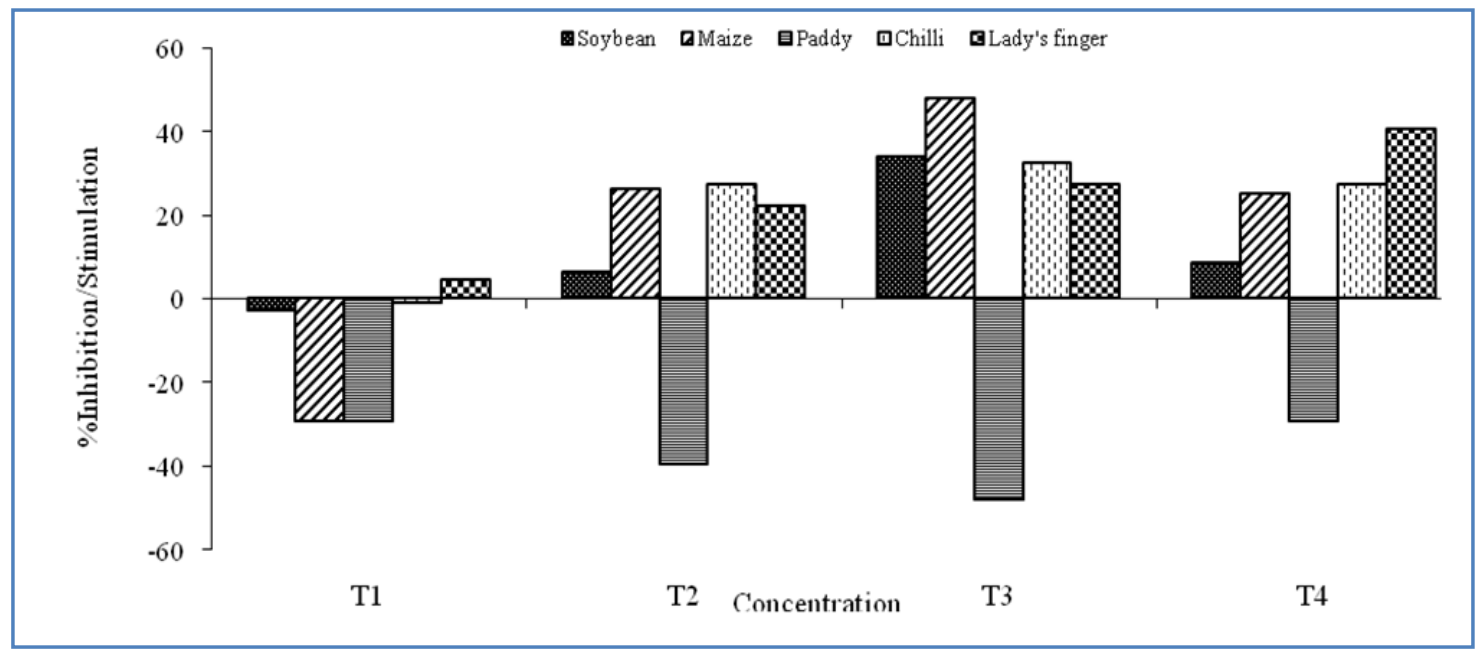

Figure 5 Inhibitory (-) or stimulatory (+) effects on shoot length of five common homegarden crops treated with different concentrations $\left(\mathrm{T}_{0}=0 \%, \mathrm{~T}_{1}=20 \%, \mathrm{~T}_{2}=40 \%, \mathrm{~T}_{3}=80 \%, \mathrm{~T}_{4}=100 \%\right)$ of aqueous leaf extract of C.reticulata under pot culture. 
Table 5 Effects of aqueous leaf extracts of $C$. reticulata on various initial growth parameters of tested crops under pot culture.

\begin{tabular}{|c|c|c|c|c|c|c|}
\hline Treatments & Parameter & Soybean & Maize & Paddy & Chilli & Lady's finger \\
\hline \multirow[t]{4}{*}{ Control } & Germination $\%$ & 77.1 & 83.2 & 71.1 & 77.5 & 72.1 \\
\hline & Shoot length $(\mathrm{cm})$ & 32.3 & 20.2 & 9.6 & 17.2 & 18.2 \\
\hline & Root length (cm) & 24.5 & 24.6 & 18.2 & 18.4 & 10.2 \\
\hline & Dry matter (g/plant) & 1.94 & 0.74 & 0.53 & 0.48 & 1.2 \\
\hline \multirow[t]{4}{*}{20 Percent } & Germination $\%$ & 81.6 & 87.3 & 73.4 & 74.84 & 74.0 \\
\hline & Shoot length $(\mathrm{cm})$ & 31.4 & 14.3 & 6.8 & 17.0 & 19.0 \\
\hline & Root length (cm) & 23.5 & 17.8 & 18.0 & 18.7 & 12.9 \\
\hline & Dry matter (g/plant) & .178 & 0.61 & 0.65 & 0.41 & 1.1 \\
\hline \multirow[t]{4}{*}{40 Percent } & Germination $\%$ & 84.9 & 88.4 & 81.9 & 77.6 & 77.1 \\
\hline & Shoot length $(\mathrm{cm})$ & 33.4 & 31.5 & 5.8 & 21.9 & 22.2 \\
\hline & Root length (cm) & 26.3 & 28.7 & 18.3 & 22.3 & 12.8 \\
\hline & Dry matter (g/plant) & 2.1 & 0.92 & 0.55 & 0.37 & 1.46 \\
\hline \multirow[t]{4}{*}{80 Percent } & Germination $\%$ & 84.2 & 89.8 & 85.9 & 82.0 & 80.6 \\
\hline & Shoot length $(\mathrm{cm})$ & 43.2 & 29.9 & 5.0 & 22.8 & 23.2 \\
\hline & Root length $(\mathrm{cm})$ & 33.7 & 29.4 & 17.3 & 22.3 & 12.3 \\
\hline & Dry matter (g/plant) & 3.14 & 1.01 & 0.58 & 0.41 & 1.53 \\
\hline \multirow[t]{4}{*}{100 Percent. } & Germination $\%$ & 92.1 & 90.4 & 90.4 & 85.6 & 85.2 \\
\hline & Shoot length $(\mathrm{cm})$ & 35.1 & 25.3 & 6.8 & 21.9 & 25.6 \\
\hline & Root length (cm) & 31.1 & 27.9 & 19.2 & 22.3 & 13.2 \\
\hline & Dry matter (g/plant) & 2.68 & 0.91 & 0.54 & 0.40 & 1.44 \\
\hline \multirow[t]{4}{*}{ LSD@5\% } & Germination & 8.76 & 7.02 & 6.57 & 6.34 & 4.92 \\
\hline & Shoot length & 2.25 & 2.32 & 0.56 & 1.85 & 2.46 \\
\hline & Root length & 0.76 & 0.85 & 1.35 & 1.23 & 0.95 \\
\hline & Dry matter & 0.33 & 0.46 & 0.06 & 0.75 & 0.91 \\
\hline
\end{tabular}

\subsection{Pot Culture under net house condition}

\subsubsection{Effects of aqueous leaf extracts on seed germination}

Under net house condition leaf extract of C.reticulata promoted the germination of all the test crops at all concentrations except in chilli (20\%) where it showed some inhibitory effect leading to lower germination percent (Table 5). The stimulatory effect was clearly visible at higher concentration (Figure 4) and the highest stimulatory effect $(19.46 \%)$ was observed in soybean at 100 percent concentration followed by lady's finger (18.13\%) and paddy $(17.23 \%)$ at the same level. Among the test crops, lady's finger and paddy showed a very clear promotion trend in seed germination with increase concentration of leaf extract (Figure 4)

\subsubsection{Effects of aqueous leaf extracts on shoot length}

The results obtained for shoot elongation shows opposite trend than the seed germination and the shoot elongation was inhibited by the application of leaf extract in paddy at all concentrations, the maximum inhibition being at 80 percent concentration (Table 5). All other test crops except lady's finger too experienced inhibition on shoot length at lowest concentration (20\%). Among the tested crops, lady's finger showed clear promotion trend in shoot elongation along concentration gradient whereas other species showed a mixed response (Figure 5). The promotion of shoot length was achieved at 80 percent concentration in soybean (33.75\%), maize $(48.02 \%)$ and chilli $(32.56 \%)$ while the lowest inhibition $(1.16 \%)$ was at 20 percent concentration in chilli and highest $(29.21 \%)$ in maize at the same concentration. Stimulatory effect was maximum in maize $(48.02 \%)$ at 80 percent, while lowest $(4.4 \%)$ at 20 percent in lady's finger (Figure 5). The maximum inhibitory effect $(47.92 \%)$ was recorded in paddy at 80 percent concentration containing treatment.

\subsubsection{Effects of aqueous leaf extracts on root length}

Results of the study revealed that the extract has stimulatory effect at all concentration on the chilli and lady finger crops and the rate of growth improvement was positively linked to the extract concentration (Table 4, Figure. 4). The root growth was inhibited at lower concentration (20\%) in soybean and paddy crops; though it was not significant for these two crops but the inhibition was highly conspicuous at the same concentration in maize (Table 5). The root length in paddy was slowly promoted due to addition of the leaf extract compared to all other crops which showed vigorous increase in root length. The highest improvement in root length was recorded in soybean at 80 percent concentration $(33.7 \%)$ and it was followed by 100 percent (29.41\%) in lady's finger (Figure 6). 


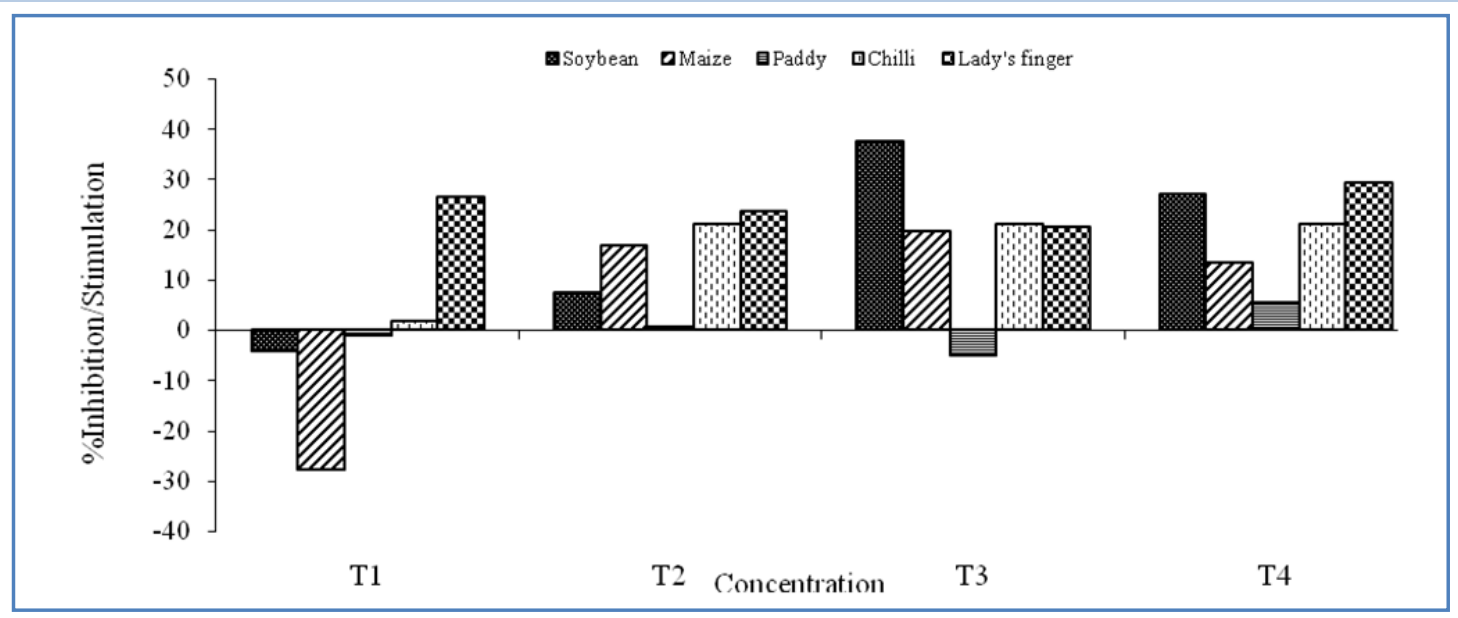

Figure 6 Inhibitory (-) or stimulatory (+) effects on root length of five common homegarden crops treated with different concentrations $\left(\mathrm{T}_{0}=0 \%, \mathrm{~T}_{1}=20 \%, \mathrm{~T}_{2}=40 \%, \mathrm{~T}_{3}=80 \%, \mathrm{~T}_{4}=100 \%\right)$ of aqueous leaf extract of C.reticulata under pot culture.

\subsubsection{Effects of aqueous leaf extracts on dry matter}

Dry matter of chilli was inhibited at all the concentrations ranging from $14.29 \%$ (20 and 80 percent) to $23.81 \%$ at 40 percent concentration. Inhibition was also observed at lower concentration (20\%) in soybean (8.25\%) and maize (17.57\%) and lady's finger $(8.33 \%)$. A clear stimulatory effect on dry matter was observed in paddy at all concentrations (Table 5, Figure 7). A maximum increase in dry matter (61.86\%) was achieved at 80 percent in soybean and lowest $(4.65 \%)$ in paddy at 40 percent concentration. However, the stimulatory effects in dry matter accumulation in the test crop were not directly proportional to leaf extract concentration (Figure 7).

Results of present study revealed that the irrigation with the different concentrations of leaf extracts have a mixed effect on the root and shoot elongation under pot culture. Most of the initial growth parameters were stimulated by the application of leaf extract under pot culture (Figures 4-7). Low concentration of $C$. reticulata leaf extracts inhibited root and shoot growth. Except the paddy, all other tested crops were stimulated for their initial growth characters resulting into better dry matter yield. Unlike the present finding many other studies have shown that the concentrated tuber extract of Cyperus rotundus impeded the radical elongation of cucumber, radish, onion and tomato (Meissner et al., 1982).

The effect of leaf extract on root and shoot growth was inversely proportional to concentration and higher concentration retarded the growth of both root and shoot and eventually reduced the seedling length. Leachate solution of Capsicum inhibited the germination of Vigna radiata, upon treatment with 50 or $75 \%$ it affected the root and shoot growth (Swami Rao \& Reddy, 1984; Siddiqui \& Zaman, 2005; Uddin et al., 2010), however the present findings do not agree with the above. Nevertheless, leaf extracts inhibited the growth of seedlings to some extent.

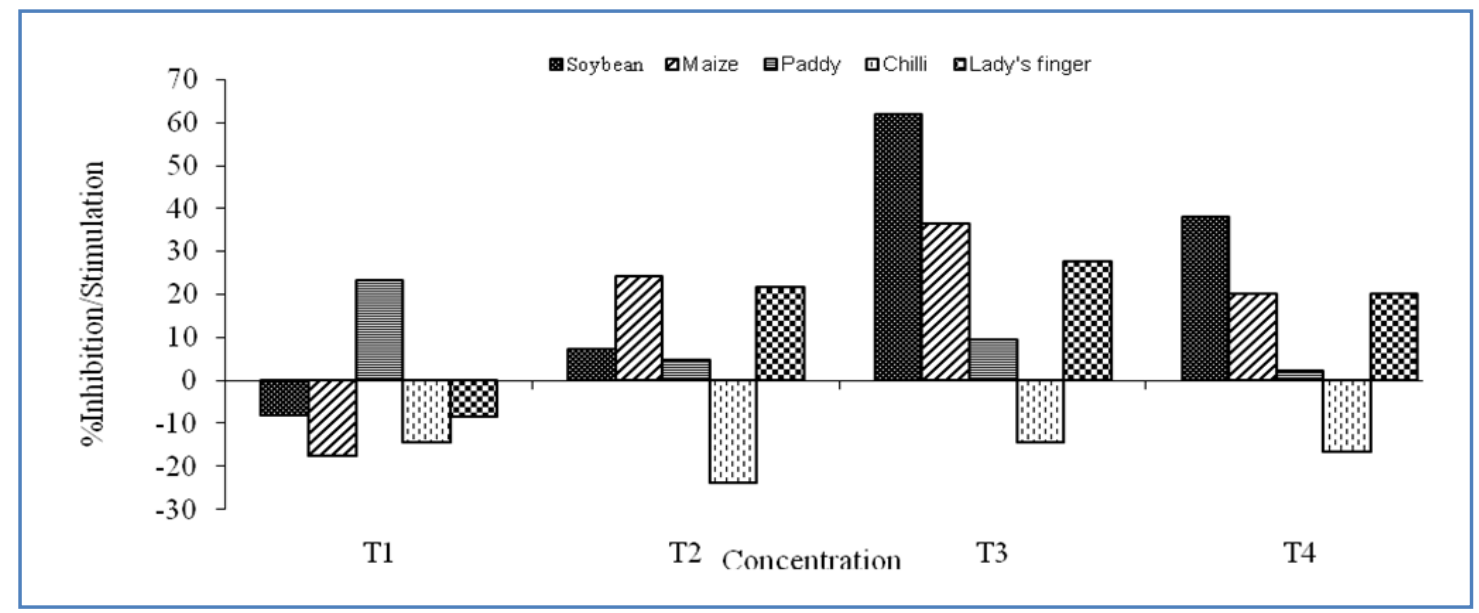

Figure 7 Inhibitory (-) or stimulatory (+) effects on dry matter percentage of five common homegarden crops treated with different concentrations $\left(\mathrm{T}_{0}=0 \%, \mathrm{~T}_{1}=20 \%, \mathrm{~T}_{2}=40 \%, \mathrm{~T}_{3}=80 \%, \mathrm{~T}_{4}=100 \%\right)$ of aqueous leaf extract of C.reticulata under pot culture. 
However, in other studies of the same author, suggested that the leaf extract solution not only reduced the germination (Sahoo et al., 2007) but also reduced the rate of germination and may cause complete failure of germination (Rice, 1984). Various other studies conducted elsewhere also revealed allelopathic suppression in soybean, maize and chilli (Sahoo et al., 2010). Melia azaderach, Morus alba and Moringa oleifera leaf leachates inhibited the germination, radicle and plumule growth of soybean (Kumar et al., 2009). However, leaf leachates of Aporusa octandra, Anthocephalus chinensis and Albizia procera did not affect the germination and radicle length of soybean (Kumar et al., 2008). Teak and subabul leaf extracts inhibited the radicle extension of maize (Lalmuanpuii \& Sahoo, 2011). Leaf extracts of selected legumes were reported to have inhibitory effect on seedling growth of maize and rice (Akobundu, 1986). The leaf extract solution is nevertheless important which may not only affect percent germination (Sahoo et al., 2007) but also the rate of germination and could result in complete failure of germination (Narwal, 1994; Mughal, 2000). In present study, chilli and paddy were the most affected test crops. In the former, dry matter while in latter the shoot length were significantly $(\mathrm{p}<0.05)$ inhibited at all concentrations.

\section{Conclusions}

Present study provides the evidence of $C$. reticulata having allelopathic potential which reduces the germination under bioassay as well suppresses the growth and development of the test crops under the pot culture. Nevertheless, the allelochemical potential and phytotoxic nature of $C$. reticulata might be due to complex mixture of components which might be strong inhibitors for growth and development of associated plants, however, further investigations, are essential to characterize the active compound(s) of the extract responsible for its activity and to examine the effect of $C$. reticulata extract against a wider range of receptor plants. Though laboratory bioassays are of great importance to single out the allelopathic effect, however extensive field studies may be recommended.

\section{Acknowledgements}

This study was financial supported by the Council of Scientific and Industrial Research, New Delhi (Grant No. 38 (1149) 07/ EMR- II, Dated. 30.03.2007 to Dr. U.K. Sahoo).

\section{Conflict of interest}

Authors would hereby like to declare that there is no conflict of interests that could possibly arise.

\section{References}

Ahmed R, Uddin MB, Hossain MK (2004) Allelopathic effects of leaf of extracts of Eucalyptus camaldulensis Dehn. on agricultural crops. Bangladesh Journal of Botany 33: 79-84.
Akobundu IO (1986) Allelopathic potentials of selected legume species. In: Resource and Crop Management Program., Institute of Tropical Agriculture, Ibadan, Nigeria, Annual Report 1986, pg. 15-19.

Assaeed AM, Al-Doss AA (1997) Allelopathic effects of Rhazya stricta on seed germination of some range plant species. Annals of Agricultural Science, Ain-Shams University Cairo 42: 159 -167.

Bhatt BP, Todaria NP (1990) Studies on the allelopathic effects of some agroforestry tree crops of Garhwal Himalaya. Agroforestry System 12: 251-255. doi: 10.1007/BF00137287.

Chou CH (1992) Allelopathy in relation to agricultural productivity in Taiwan: Problems and prospects. In: Rizvi SJH, Rizvi V (Eds.), Allelopathy: Basic and applied Aspects. Chapman and Hall, London Pp. 179-204.

Chou CH, Leu LL (1992) Allelopathic substances and interactions of Delonix regia (BOJ) Raf. Journal of Chemical Ecology 18: 2285-2303. doi: 10.1007/BF00984951.

Cvetnic Z, Vladimir-Knezević S (2004) Antimicrobial activity of grapefruit seed and pulp ethanolic extract. Acta pharmaceutica 54: 243-250.

Daniel WG (1999) Historical review and current models of forest succession and interference. CRC Press Publication, LLC Pp. 237-251.

Darjari BB (2013) Comparison of leaf compounds of sweet and sour orange (Citrus sp.). International Journal of Advanced Biological and Biomedical Research 1: 1558-1568.

Fujihara S, Shimizu T (2003) Growth inhibitory effect of peel extract from Citrus junos. Plant Growth Regulation 39: 223233. doi: 10.1023/A:1022899119374.

Gholami BA, Faravani M, Kashki MT (2011) Allelopathic effects of aqueous extract from Artemisia kopetdanghensis and Satureja hortensison growth and seed germination of weeds. Journal of Applied Environmental and Biological Sciences 1: 283-290.

Gill AS (1992) Allelopathy in agroforestry. In: Tauro, P. \& Narwal, S.S. (Eds), Allelopathy in Agroecosystems (Agriculture and Forestry) Indian Society of Allelopathy, Haryana Agriculture University, Hissar, India.

Hättenschwiler S, Vitousek PM (2000) The role of polyphenols in terrestrial ecosystem nutrient cycling. Trends in ecosystems and Ecology 15: 238-243. doi:10.1016/S01695347(00)01861-9. 
Inderjit I (1996) Plant phenolics in Allelopathy. Botanical Review 62: 186-202. doi: 10.1007/BF02857921.

Inderjit I, Malik AU (2002) Chemical Ecology of Plants: Allelopathy in Aquatic and Terrestrial Ecosystems. Birkhauser-Verlag, Berlin. 10.1007/978-3-0348-8109-8

Jayaprakasha GK, Singh RP, Pereira J, Sakariah KK (1997) Limonoids from Citrus reticulata and their moult inhibiting activity in mosquito Culex quinquefaasciatus larvae. Phytochemistry 44:843-846. doi:10.1016/S00319422(96)00589-4.

Kato-Noguchi H, Tanaka Y (2003) Allelopathic potential of citrus fruit peel and abscisic acid-glucose ester. Plant Growth Regulation 40: 117-120. doi: 10.1023/A:1024291428234.

Kumar M, Lakiaing JJ, Siiolyne S (2008) Tree crop interaction in agroforestry systems of Mizoram. Journal of Tropical Forest Science 20: 91-98.

Kumar M, Malik V, Joshi M (2009) Allelopathic effects of Melia azaderach, Morus alba and Moringa oleifera on germination, radical and plumule growth of Glycine max. Range Mangement and Agroforestry 30:167-168

Lalmuanpuii R, Sahoo UK (2011) Allelopathic effects of Tectona grandis L. and Mikania micrantha $\mathrm{L}$. on germination of Zea mays L. and Oryza sativa L. under laboratory condition. Science Vision 11: 208-213.

Lodhi MAK (1978) Allelopathic effects of decaying litter of dominant trees and their associated soil in a lowland forest community. American Journal of Botany 65: 340-344.

May FE, Ash JE (1990) An assessment of the allelopathic potential of Eucalyptus. Australian Journal of Botany 38: 245 - 254. doi:10.1071/BT9900245.

Meissner R, Nel PC, Smith NSH (1982) The residual effect of Cyperus rotundus on certain crop plants. Agroplantae 14: 4753.

Mughal AH (2000) Allelopathic effect of leaf extract of Morus alba L. on germination and seedling growth of some pulses. Range Management and Agroforestry 21: 164-169.

Narwal SS (1994) Allelopathy in crop production. Scientific Publisher, Jodhpur, India, 288 pg

Nishida N, Tomotsu S, Nagata N, Saito C, Sakai A (2005) Allelopathic effects of volatile monoterpenoids produced by Salvia leucophylla: Inhibition of cell proliferation and DNA synthesis in root apical meristem of Brassica campestris seedlings. Journal of Chemical Ecology 31: 1187-1203.
Rice EL (1984) Allelopathy. $2^{\text {nd }}$ Ed. Academic Press, Inc., Orlando, FL, 353.

Rafiqul Hoque ATM, Uddin MB, Ahmed R, Hossain MK (2003) Suppressive Effects of Aqueous Extracts of Azadirachta indica Leaf on Some Initial Growth Parameters of Six Common Agricultural Crops. Asian Journal of Plant Sciences 2: 738-742. doi: 10.3923/ajps.2003.738.742.

Saeed GA, Ramadan NA (2006) Allelopathic effect of Citrus trees on some soil fungi. Ninth Arab Congress of Plant Protection, 19-23 November 2006, Damascus, Syria, E-158.

Sahoo UK (2013) Allelopathic studies of understory weeds by agroforestry trees in homegardens of Mizoram. Journal of Experimental Biology and Agricultural Sciences 1: 248-257.

Sahoo UK, Upadhyaya K, Meitei CB (2007) Allelopathic effects of Leucaena leucocephala and Tectona grandis on germination and growth of maize. Allelopathy Journal 20: 135144.

Sahoo UK, Jeeceelee L, Vanlalhriatpuia K, Upadhyaya K, Lalremruati JH (2010) Allelopathic effects of leaf leachates of Magnifera indica L. on initial growth parameters of few homegarden food crops. World Journal of Agricultural Sciences 6: 579-588.

Sawabe A, Morita M, Kiso T, Kishine H, Ohtsubo Y, Minematsu Y, Matsubara Y, Okamoto T (1999) Isolation and characterization of new limonoid glycosides from Citrus unshiu peels. Carbohydrate Research 315: 142-147. doi:10.1016/S0008-6215(98)00328-0.

Seigler DS (1996) Chemistry and mechanism of allelopathic interaction. Agronomy Journal 88: 876-885. doi:10.2134/agronj1996.00021962003600060006x.

Siddiqui ZS, Zaman AU (2005) Effects of Capsicum leachates on germination, seedling growth and chlorophyll accumulation in Vigna radiata (L.) Wilczek seedling. Pakistan Journal of Botany 37: 941-947.

Stahl E (1969) Thin layer Chromatography, Springer-Verlag, Berlin, Pp. 494.

Swami Rao N, Reddy PC (1984) Studies on the inhibitory effect of Eucalyptus (hybrid) leaf extracts on the germination of certain food crops. The Indian Forester 110: 218-222

Uddin MB, Ahmed R, Hossain MK (2000) Allelopathic potential of water extracts of Leucaena leucocephala leaf on some agricultural crops in Bangladesh. The Chittagong University Journal of Science 24: 121-127. 
Velu G, Srinivasan PS, Ali AM, Narwal SS (1996) Phytotoxic effects of tree crops on germination and radical extension of legumes. Proceeding of International Conference on Allelopathy 1: 299-302.
Wungsintaweekul J, Sitthithaworn W, Putalun W, Pfeifhoffer HW, Brantner A (2010) Antimicrobial, antioxidant activities and chemical composition of selected Thai spices. Songklanakarin Journal of Science and Technology 32: 589598. 